\title{
Quanto vale, professor? novas estratégias, velhas concepções de avaliação no ensino jurídico*
}

\author{
How much is it worth, professor? new \\ strategies, old ideas about assessing law \\ education
}

Juliana Ferrari ${ }^{1}$

\section{Resumo}

Este estudo se propôs a analisar, a partir dos planos de curso dos professores da Faculdade de Direito de Vitória (FDV), suas percepções sobre a avaliação das atividades chamadas Teoria-Prática. Estas atividades fazem parte do projeto institucional iniciado em 2003 e tem como objetivo fundamental favorecer o desenvolvimento de competências e habilidades necessárias para o bom desempenho profissional. Como resultado, tem-se que, apesar da inclusão das atividades nos planos de curso, ainda não se percebe valorização das mesmas pelos professores, o que sugere que a avaliação no ensino superior jurídico ainda tem como foco principal a apropriação de conteúdo apenas.

Palavras-chave: Avaliação discente. Atividades teoria-prática. Ensino jurídico

\begin{abstract}
This study focuses on analyzing, from lesson plans of course professors at Faculdade de Direito de Vitória (FDV), their ideas on the assessment of the activities regarding Theory-Practice. Such activities are part of the institutional project which began in 2003 and whose main objective is enabling the development of competence and skills needed to achieve good professional performance. As a result, despite the inclusion of such kind of activities within the course lesson planning, no value regarding these actions is seen from the professors' viewpoint, what is a sign that regular evaluation through tests in higher law education focuses only on the knowledge of the content studied.
\end{abstract}

Key-words: Teachers' Evaluation. Theory-Practice Activities. Law Education 


\section{Introdução}

O curso de Direito no Brasil, talvez por ser um dos mais antigos do país, tem como uma de suas características predominantes a forte tradição de suas práticas, quais sejam, metodologia de ensino com ênfase na aula expositiva tradicional, fragmentação do saber acentuado pela unidisciplinaridade e o dogmatismo jurídico. Tentativas de avanço têm sido promovidas, principalmente em relação à legislação, com a portaria 1886/94 e a resolução no 9/2004, que determinam as diretrizes para o curso de Direito. Avanços estes que, infelizmente, parecem não ter sido capazes de ensejar significativas transformações na prática. ${ }^{2}$

A lógica da transmissão de conteúdo, tendo o professor como responsável pelo conhecimento e o aluno como parte passiva e apenas receptiva desta relação ainda é evidente nos cursos jurídicos. $\mathrm{O}$ fazer docente divide-se em exposição do conteúdo, seguido de exercícios de fixação e, finalmente, avaliação.

Avalia-se tão somente a capacidade do aluno em demonstrar se o que foi exposto foi absorvido adequadamente, e a melhor forma de se fazer isso, seguindo esta lógica, é a prova escrita. Neste sentido, avaliação confunde-se com a prova e passa a ser um momento de grande ansiedade, pois é determinante único do credenciamento de qualidade.

Críticas a esse modelo de ensino têm sido frequentes e tem feito com que iniciativas, mesmo que isoladas, sejam desenvolvidas em algumas instituições de ensino. O projeto Teoria Prática da Faculdade de Direito de Vitória (FDV) é uma destas iniciativas. Em busca de repensar a metodologia do ensino jurídico e favorecer o desenvolvimento de competências e habilidades ${ }^{3}$

2 MELO FILHO, A. Juspedagogia: ensinar direito o direito. In: OAB. Ensino jurídico: balanço de uma experiência. Brasília/ DF: OAB, 2000. p. 38.

3 O projeto Teoria Prática optou por trabalhar as expressões "competências" e "habilidades" num mesmo sentido, uma vez que não há consenso a respeito dessas expressões. Neste sentido, entende-se como competência/habilidade a capacidade de inter-relacionar "os conteúdos teóricos das disciplinas e experiência práticas que demonstrem autonomia de julgamento e de ação, de atitudes, valores e procedimentos diante de situações-problema, que se aproximem o máximo possível das condições reais de convívio social e de trabalho individual e coletivo" FINI, M. E. et al. Erros e acertos na elaboração de itens para a prova do ENEM. In: SEMINÁRIO DE LUIZ CARLOS MENEZES, 1999, São Paulo. As disciplinas e a construção de competências e habilidades. São Paulo: CEVEC, 1999. p. 7. necessárias para o bom desempenho profissional, e não apenas a apropriação de conteúdos conceituais, o projeto Teoria Prática desafia os professores a, “intensificarem o desenvolvimento de atividades que exigissem dos alunos uma postura ativa, de análise, raciocínio, reflexão e solução de problemas." 4

Este projeto iniciou-se em 2003 e já é prática institucionalizada na FDV, mas após dez anos de implementação, fica a indagação sobre a percepção dos professores sobre as atividades propostas pelo projeto. Como os professores avaliam as atividades teoria prática? A hipótese embasadora é que a avaliação de tais atividades está diretamente ligada ao valor que se dá a elas e, consequentemente, ao desenvolvimento de competências. Em outras palavras, a aplicação de tais atividades foi capaz de ensejar mudança na perspectiva dos professores sobre o desenvolvimento de conteúdos procedimentais (saber fazer) e atitudinais (saber fazer bem ${ }^{5}$ ), além dos conceituais (saber)?

Para responder estas perguntas foi feito um levantamento dos planos de curso dos professores da FDV porque é nos planos que são apresentadas as atividades Teoria Prática e definidas as formas de avaliação. Foram analisados 63 planos de curso do primeiro semestre de 2013. Os 63 planos representam os 55 professores da instituição. A diferença numérica se dá devido ao fato de alguns professores lecionarem mais de uma disciplina.

Vale destacar que, muitas vezes, o que está definido no plano representa as intenções do professor, ou seja, alterações podem ocorrer durante o desenvolvimento da disciplina. Mesmo assim, parte-se do pressuposto de que a própria definição representa o desejo inicial do

4 FACULDADE DE DIREITO DE VITÓRIA. Projeto teoria prática. Vitória: FDV, 2008. p. 7.

5 "Saber fazer bem" no sentido dado por Rios, qual seja: "Afirmo que o saber fazer bem tem uma dimensão técnica, a do saber e do saber fazer, isto é, do domínio dos conteúdos de que o sujeito necessita para desempenhar o seu papel, aquilo que se requer dele socialmente, articulado com o domínio das técnicas, das estratégias que permitam que ele, digamos, 'dê conta de seu recado', em seu trabalho. Mas é preciso saber bem, saber fazer bem, e o que me parece nuclear nesta expressão é este pequeno termo - 'bem' - porque ele indicará tanto a dimensão técnica - 'eu sei bem geografia', [...], - quanto uma dimensão política -'eu faço bem o meu trabalho de geógrafo [...], isto é, vou ao encontro daquilo que é desejável, que está estabelecido valorativamente com relação à minha atuação". RIOS, T. A. Compreender e ensinar: por uma docência da melhor qualidade. São Paulo: Cortez, 2006. p. 47. 
professor, podendo, portanto, ser levado em consideração para análise de suas percepções.

Passa-se agora a apresentar o projeto Teoria Prática da FDV, para, em seguida, discutir as características da avaliação no ensino superior jurídico e, apresentar a análise dos planos de curso.

\section{Projeto TEORIA PRATICA da FDV}

O projeto teoria prática da FDV nasce do desejo institucional de desenvolver em seu corpo discente competências/habilidades que vão além do acúmulo de conhecimento teórico. Mais do que "saber", a preocupação gira em torno do "saber fazer", essencial para as exigências profissionais atuais.

Esta mudança de perspectiva (além de saber, é necessário saber fazer e saber fazer bem) demanda mudança na metodologia de ensino jurídico. Para saber fazer, o aluno deve realizar operações do pensamento que não se limitam à mera memorização de conteúdo. A postura passiva cede lugar a uma postura ativa, que reflete, cria, analisa, sugere e resolve problemas. Da mesma forma, a aula expositiva tradicional, que exige do aluno apenas a capacidade de cópia e repetição deve ser repensada.

É importante esclarecer que não se defende a extinção da aula expositiva, o que se argumenta é que ela não deve ser a única possibilidade metodológica para o ensino jurídico, porque seu uso exclusivo pode restringir as possibilidades de desenvolvimento de habilidades/competências nos alunos. Vale destacar também que a aula expositiva dialogada representa um avanço em relação à aula expositiva tradicional e pode ser eficiente na mudança do papel do aluno defendida neste estudo.

A ênfase na articulação teoria/prática na aula jurídica é a base do projeto Teoria Prática e demanda dos professores a inclusão de, pelo menos, uma atividade Teoria Prática em sua disciplina. Esta articulação é entendida como:

\footnotetext{
a vinculação entre a reflexão da ação ou o próprio exercício da ação, com o conhecimento científico e as proposições normativas, a fim de promover, além do conhecimento da teoria, sua melhor apreensão e, especialmente, o desenvolvimento de habilidades e competências ${ }^{6}$
}

Dentre as várias atividades Teoria Prática usadas pelos professores desde o início do projeto estão o roteiro de leitura, o estudo de meio, o ensino com pesquisa, a simulação jurídica e a oficina jurídica ${ }^{7}$. Todas elas permitem ao aluno desenvolver as habilidades/competências eleitas pela instituição para serem trabalhadas pelos alunos, quais sejam:

1. Leitura, compreensão e elaboração textos, atos e documentos jurídicos ou normativos com a devida utilização das normas técnico jurídicas;

2. Expressão verbal fluente e dotada de certa formalidade;

3. Compreensão dos fenômenos sociais e políticos de seu tempo e capacidade de correlacioná-los com o conhecimento jurídico apreendido, de modo a se comprometerem com a apresentação de propostas voltada à busca de soluções jurídicas para as demandas sociais contemporâneas;

4. Compreensão dos fundamentos filosóficos e teóricos do direito e capacidade de relacioná-los com sua aplicação prática;

5. Capacidade de interpretar e aplicar as normas jurídicas (regras e princípios);

6. Raciocínio e argumentação jurídica;

7. Utilização do raciocínio jurídico, lógico, argumentativo e dialético;

8. Capacidade de tomar decisões jurídicas fundamentadas;

9. Capacidade de avaliar o cabimento e pertinência do uso de métodos alternativos na solução de conflitos;

10. Utilização de processos, atos e procedimentos para atuação técnico-jurídica, em diferentes instâncias;

11. Capacidade de enfrentar situações novas e buscar soluções inovadoras;

12. Capacidade de demonstrar consciência crítica na análise do ordenamento jurídico;

13. Capacidade de utilizar métodos de investigação científica;

14. Capacidade de utilizar modernos recursos de informações e fontes não jurídicas;

15. Capacidade de trabalhar em equipe, respeitando a diferentes pontos de vista, debatendo numa perspectiva jurídica; conciliando interesses na tomada de decisão;

7 Tais estratégias de ensino, que a FDV chama de atividades Teoria Prática, são geralmente denominadas de métodos participativos. GHIRARDI, J. G. (Coord.). Métodos de ensino em Direito. São Paulo: Saraiva, 2009.
${ }_{6}$ FACULDADE DE DIREITO DE VITÓRIA. Projeto Teoria Prática. Vitória, 2008, p. 14. 
16. Domínio de uma língua estrangeira que permita o desempenho eficiente no âmbito jurídico;

17. Capacidade de trabalhar em equipe interdisciplinar como expert em direito.

18. Capacidade de conhecer o perfil do seu interlocutor e o contexto de sua inserção na sociedade, conduzindo o relacionamento orientado pelas características e peculiaridades detectadas e pelas normas da ética profissional. ${ }^{8}$

Conforme o exposto, o potencial de desenvolvimento de habilidades/competências que as atividades Teoria Prática podem proporcionar é bastante significativo, por isso, a elaboração e realização do referido projeto é louvável e essencial para contribuir positivamente para o ensino jurídico.

\section{Características da avaliação no ensino supe- rior jurídico}

As características da avaliação no ensino superior jurídico não são diferentes da sua metodologia de ensino. Em uma aula tradicional, que vê o aluno como parte passiva do processo de ensino e aprendizagem, a avaliação também deve acontecer de forma tradicional. Por isso, ainda vigora no imaginário e nas práticas do docente do curso de Direito que avaliar é medir o conhecimento, é contabilizar resultados, é obter o produto final.

Como consequência, tem-se que a avaliação serve para verificar se o conteúdo apresentado foi absorvido adequadamente pelo aluno, geralmente por meio da prova escrita. A rotina fica estabelecida em aula expositiva, seguida de exercícios de fixação e prova. A competência/ habilidade que, geralmente, é avaliada é a capacidade de armazenamento de informação.

A inclusão de atividades Teoria Prática, como dito anteriormente, tem o objetivo de desenvolver outras competências/habilidades, que vão além da memorização e exposição de conteúdo. Elas fazem parte do planejamento de aula dos professores da instituição justamente com o objetivo de favorecer o desenvolvimento de competências previstas para o curso de Direito da FDV. A crença inicial é de que tais atividades seriam capazes
8 FACULDADE DE DIREITO DE VITÓRIA. Projeto Teoria Prática. Vitória: FDV, 2008. p. 20. de ensejar mudança na metodologia do ensino jurídico, o que demanda mudança na avaliação também.

Isso porque entende-se a avaliação como parte fundamental do processo de ensino-aprendizagem, não sendo possível sua concepção isoladamente, dissociada da aula. Avalia-se o que foi trabalhado, discutido em sala de aula, mas não com o objetivo de cristalizar o registro de nota, "transformando a avaliação numa contabilização de resultados", como é feito na avaliação somativa.

O que se pretende para o ensino como um todo, incluindo-se o superior jurídico, apesar de ainda ser, nas palavras de Hadji (2001, p.20) "uma utopia promissora", é a prática da avaliação formativa, em que o resultado é considerado um guia do que precisa ser desenvolvido. Em outras palavras, o resultado não é produto final, e sim, parte de um processo constante que tem como objetivo fundamental melhorar a aprendizagem.

O desenvolvimento e avaliação das atividades Teoria Prática vão ao encontro da formatividade da avaliação. Nas palavras de Romanowski e Wachowicz "nossa sugestão é que a metodologia de ensino encampe a epistemologia da prática, pois, ao assumi-la, suas possibilidades de mudança estarão favorecidas na direção da avaliação formativa. A prática pode ser observada cotidianamente e, portanto, avaliada". ${ }^{10}$

Há, entretanto, outro argumento que poderia justificar a necessidade de se avaliar as atividades Teoria Prática e que está ligado ao próprio sentido de avaliar. De acordo com o dicionário Houaiss, avaliar é "estabelecer a valia, o valor [...], determinar a quantidade e a qualidade [...], apreciar o mérito, o valor de; estimar"11. Além disso, a avaliação "expressa a adequação (ou a não adequação) percebida entre a relação atual do aluno com o saber, ob-

9 ROMANOWSKI, J. P.; WACHOWICZ, L. A. Avaliação formativa no ensino superior: que resistências manifestam os professores e alunos? In: ANASTASIOU, L. G. C.; ALVES, L. P (Org.). Processos de ensinagem na universidade: pressupostos para as estratégias de trabalho em aula. Joinville, SC: Univille, 2006. p. 125.

${ }^{10}$ ROMANOWSKI, J. P.; WACHOWICZ, L. A. Avaliação formativa no ensino superior: que resistências manifestam os professores e alunos? In: ANASTASIOU, L. G. C.; ALVES, L. P (Org.). Processos de ensinagem na universidade: pressupostos para as estratégias de trabalho em aula. Joinville, SC: Univille, 2006. p.137.

${ }^{11}$ HOUAISS. Dicionário Houaiss da Língua Portuguesa. Rio de Janeiro/RJ: Instituto Antônio Houaiss de Lexicografia, 2001. 
jeto da avaliação, e a relação ideal do aluno com o saber, objeto do "desejo" institucional. É em nome dessa relação que é declarado o valor do aluno.

Significa dizer que o reconhecimento da capacidade do aluno depende do resultado de sua avaliação. Ora, todos querem ser reconhecidos, valorizados, avaliados positivamente, portanto, a avaliação acaba direcionando os esforços do aluno. ${ }^{12}$

Por isso, propor e avaliar as atividades Teoria Prática nas disciplinas do curso é mostrar ao aluno que o desenvolvimento das habilidades/competências selecionadas pela instituição é valorizado, tanto pelo professor quanto pela própria instituição. É mostrar ao aluno que o "saber fazer" é tão importante quanto o "saber", é ser coerente com o perfil do egresso que está previsto no projeto político pedagógico da FDV.

\begin{abstract}
O profissional formado pela FDV deve ser capaz de perceber a amplitude do conhecimento e do patrimônio cultural humano, numa dimensão histórica e política. Ao lado de uma estrutura intelectual que transcenda os domínios do jurídico, deve possuir sensibilidade em relação às diferenças socioculturais para transitar nos diversos espaços nacionais e internacionais. Deve, ainda, ser capaz de colocar em ação competências e habilidades, nos diversos papéis possíveis a um profissional da área jurídica, compreendendo o Direito como parte do conhecimento humano e suas relações e interfaces com a própria condição humana. Deve ser sensível e atento às consequências dos percursos jurídicos na vida pública e privada dos cidadãos. Espera-se, ainda, que o profissional domine mais de uma língua, além da materna, para dar conta dos desafios globais. ${ }^{13}$
\end{abstract}

Da mesma forma, propor atividade Teoria Prática, mas não avaliá-las evidencia aos alunos que elas não são “tão importantes assim", que eles deveriam priorizar a prova, porque é nela que seu valor será declarado. Como consequência, tem-se que aluno faz as atividades porque fazem parte do plano de curso do professor, mas não as considera parte relevante de sua aprendizagem, podendo passar a enxerga-la como desnecessária e irrelevante.

Vale destacar que esta também pode ser a visão do professor, que, fruto da tradição do ensino jurídico, equivale a avaliação tão somente à prova escrita, e valoriza

\footnotetext{
${ }^{12}$ HADJI, C. Avaliação desmistificada. Porto Alegre: Artmed, 2001. p. 44.

${ }^{13}$ FACULDADE DE DIREITO DE VITÓRIA. Projeto Teoria Prática. Vitória: FDV, 2008. p. 18.
}

apenas a capacidade de memorização do aluno. Por último, não propor atividades Teoria Prática é permanecer enraizado em um modelo de ensino que já não atende às necessidades da profissão.

É em busca de conhecer a visão dos professores da FDV sobre as atividades Teoria Prática que esse artigo se dedica agora, ao analisar os planos de curso adotados neste primeiro semestre de 2013.

\section{0 que dizem os planos de curso dos profes- sores}

Todo início de semestre os professores da FDV devem enviar seus planos de curso com as mudanças e adaptações que julgarem necessárias. $O$ plano deve ser bem detalhado e conter os seguintes itens: unidades, objetivos, aulas, técnica de ensino, desenvolvimento da atividade de aplicação, bibliografia básica e complementar e avaliação.

A análise concentrou-se no item técnica de ensino, desenvolvimento da atividade de aplicação e avaliação, já que o objetivo foi verificar se as atividades Teoria Prática estavam sendo contempladas nos planos, avaliadas e com que "valor". O resultado desta análise segue abaixo.

Dos 63 planos de curso analisados, 43 (68\%) atribuem nota às atividades Teoria Prática, 13 (21\%) propõem atividades indicadas na coluna técnica de ensino, mas não atribuem nota a elas, ou seja, elas não constam no item avaliação. Vale destacar que, em alguns planos, a atividade não constava no item técnica de ensino mencionado anteriormente, mas sim no item desenvolvimento de atividade de aplicação. Entretanto, pela explicação da atividade, podia-se inferir que se tratava de uma atividade que proporcionava relação Teoria Prática. Sete (11\%) planos não continham proposta de atividades Teoria Prática. O gráfico abaixo apresenta esses dados.

Gráfico 1 - Atividades Teoria Prática nos Planos de Curso

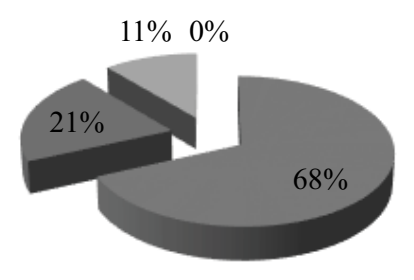

$$
\begin{aligned}
& \text { há atividade teoria- } \\
& \text { prática avaliada } \\
& \text { há atividade teoria- } \\
& \text { prática não avaliada } \\
& \text { não há atividade } \\
& \text { teoria-prática }
\end{aligned}
$$

O fato de $68 \%$ dos planos atribuírem nota a uma atividade diferente da tradicional "prova" sugere que a 
maioria dos professores já percebeu que outras formas de avaliação podem fazer parte do ensino superior jurídico. O trabalho desenvolvido na instituição de repensar a avaliação e desenvolver novas estratégias avaliativas, a partir de atividades que demandem dos alunos, não apenas conhecimento teórico, mas outras competências e habilidades parece estar no caminho certo.

Uma análise mais profunda, entretanto, indica como a prova ainda é muito valorizada pelos professores. Quando o foco da análise dos 43 planos que avaliam com nota as atividades Teoria Prática é o valor numérico dado a tais atividades, tem-se que a maioria ( $83 \%$ ou 36 planos) atribui no máximo 3 pontos a elas, conforme indicado no gráfico abaixo.

Gráfico 2 - Maior pontuação atribuída a uma atividade teoriaprática em cada um dos planos analisados

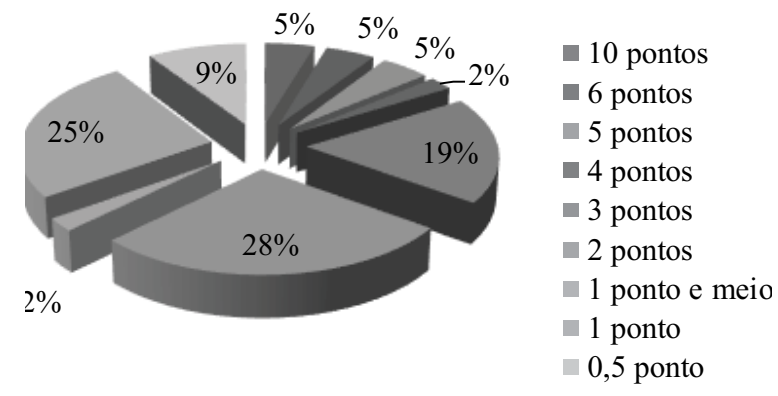

Depreende-se ainda dos dados que 2 (5\%) planos possuem atividade Teoria Prática valendo 10 pontos, 2 (5\%) possuem atividade Teoria Prática valendo 6 pontos, 2 (5\%) possuem atividade Teoria Prática valendo 5 pontos, $1(2 \%)$ possui atividade Teoria Prática valendo 4 pontos, 8 (19\%) possuem atividade Teoria Prática valendo 3 pontos, 12 (28\%) possuem atividade Teoria Prática valendo 2 pontos, 1 (2\%) plano possui atividade Teoria Prática valendo 1 ponto e meio, 11 (25\%) planos possuem atividade Teoria Prática valendo 1 ponto e 4 (9\%) planos possuem atividade Teoria Prática valendo meio ponto.

A diferença de atribuição de nota demonstra a valorização, o valor dado pelos professores a este tipo de atividade. Se levarmos em consideração os dados do próximo gráfico, que apresenta a quantidade de atividades teoria-prática por semestre, veremos que, geralmente, $o$ bimestre é composto por duas notas, conforme a seguir:
Gráfico 3 - Quantidade de atividades teoria-prática por semestre em cada plano

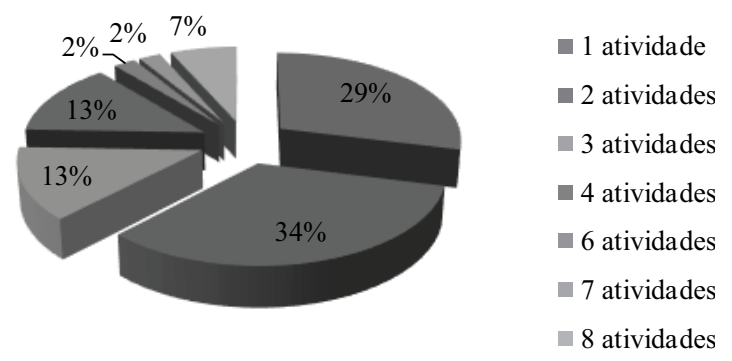

O gráfico acima mostra que 1 (2\%) plano de curso apresenta 6 atividades Teoria Prática e 1 (2\%) plano apresenta 7. Oito atividades Teoria Prática são propostas em $3(7 \%)$ planos, quatro em 6 (13\%) planos e 3 em 6 (13\%) planos. Apenas 1 atividade Teoria Prática é indicada em 13 (29\%) planos e, na maioria (15 planos ou 34\%) dos planos de curso, há previsão de 2 atividades Teoria Prática por semestre.

Portanto, como o valor médio de tais atividades é 2 pontos, pode-se inferir que em um bimestre, geralmente, a atividade Teoria Prática vale 2 e a prova vale 8 . Significa dizer que, conforme indicam os dados, para os professores da instituição, a prova tradicional vale muito mais, tem peso maior, portanto, é considerada mais adequada para avaliar o desempenho de um aluno.

O porquê desta escolha pode ser explicado pela própria trajetória do ensino superior jurídico no país e, consequentemente pela formação de seus professores. Um ensino que, desde sua fundação, possui como características marcantes o dogmatismo, a descontextualização e a unidisciplinaridade. Um ensino que tem como metodologia predominante a aula expositiva tradicional. Um ensino cujos professores são, em sua maioria, fruto deste modelo citado, apropriando-se desta experiência para lecionar, repetindo velhos modelos. Um ensino que tem como modelo de avaliação, consequentemente, a prova de conhecimento teórico, porque é o conhecimento teórico que é exigido, esperado e valorizado. A prova da $\mathrm{OAB}$ e as provas dos concursos públicos reforçam esta valorização.

Atribuir pontuação de menor valor às atividades avaliativas que são diferentes da prova tradicional de- 
monstra que a maioria dos professores do ensino superior jurídico da FDV, ainda que tenham inserido em sua prática docente, novas metodologias de ensino, como as atividades do Projeto Teoria Prática apresentados neste estudo, permanecem enraizados ao velho modelo de avaliação.

Como consequência, tem-se que o aluno, naturalmente, entende que "o que vale" é a prova, que seus esforços maiores devem ser para e na prova, porque é por meio dela que seu desempenho será qualificado. Da mesma forma, se as outras formas de avaliar, quais sejam, as atividades Teoria Prática, valem menos, pouca dedicação ou relevância será dada a elas. A mensagem que fica é que o que vale, o que ainda vale para o ensino superior jurídico é o conhecimento teórico apenas.

A valorização das competências e habilidades indicadas no projeto político pedagógico e no projeto teoria prática fica secundária, o que não deixa de ser um contrassenso com a própria proposta de formação do profissional da instituição.

Evidencia-se o desafio que se tem pela frente, qual seja, a necessidade de se investir na formação continuada dos professores de ensino jurídico que, mesmo após diversos investimentos institucionais, como cursos de capacitação pedagógica, participação em palestras e oficinas, e por mais que tenham avançado em relação à utilização de novas estratégias de ensino, ainda permanecem presos a velhas concepções de avaliação, concepções estas que fazem parte de sua própria historia docente e discente do ensino jurídico.

\section{Considerações Finais}

Este artigo se propôs a analisar, a partir dos planos de curso dos professores da FDV, o valor dado por eles às atividades Teoria Prática. O critério para definir o "valor" foi se à atividade foi atribuída nota ou não, ou seja, se fazia parte da avaliação proposta pelo professor em seu plano e qual o valor da nota.

Pelos planos, verificou-se que a maioria deles (68\%) propõe atividades Teoria Prática e as avalia, o que, inicialmente, parece ser bastante satisfatório. $\mathrm{O}$ fato dos professores incluírem as atividades Teoria Prática em seus planos é consequência do investimento feito pela instituição na efetivação do projeto Teoria Prática, inicia- do em 2003, com o objetivo de modificar a metodologia de ensino jurídico da FDV.

O que chama a atenção, entretanto, é o valor quantitativo dado a tais atividades em relação às tradicionais provas. Pela análise dos planos, constatou-se que em 63\% dos planos, há no máximo a proposta de até duas atividades Teoria Prática por semestre, e que na maioria deles (83\%) são atribuídos até três pontos a tais atividades, deixando para a prova os outros pontos restantes do bimestre. Esta diferença de pontuação sugere que, apesar da inclusão de atividades Teoria Prática nos planos de curso dos professores já ser realidade, ainda não se percebe efetiva valorização das mesmas pelos professores.

\section{Referências}

FACULDADE DE DIREITO DE VITÓRIA. Projeto Político Pedagógico. Vitória: FDV, 2007.

FACULDADE DE DIREITO DE VITÓRIA. Projeto Teoria Prática. Vitória: FDV, 2008.

FINI, M. E. et al. Erros e acertos na elaboração de itens para a prova do ENEM. In: SEMINÁRIO DE LUIZ CARLOS MENEZES, 1999, São Paulo. As disciplinas e a construção de competências e habilidades. São Paulo: CEVEC, 1999.

GHIRARDI, J. G. (Coord.). Métodos de ensino em Direito. São Paulo: Saraiva, 2009.

HADJI, C. Avaliação desmistificada. Porto Alegre: Artmed, 2001.

HOUAISS. Dicionário Houaiss da Língua Portuguesa. Rio de Janeiro/RJ: Instituto Antônio Houaiss de Lexicografia, 2001.

MELO FILHO, A. Juspedagogia: ensinar direito o direito. In: OAB. Ensino Jurídico: balanço de uma experiência. Brasília/DF: OAB, 2000.

RIOS, T. A. Compreender e ensinar: por uma docência da melhor qualidade. São Paulo: Cortez, 2006.

ROMANOWSKI, J. P.; WACHOWICZ, L. A. Avaliação formativa no ensino superior: que resistências manifestam os professores e alunos? In: ANASTASIOU, L. G. C.; ALVES, L. P (Org.). Processos de ensinagem na universidade: pressupostos para as estratégias de trabalho em aula. Joinville, SC: Univille, 2006. 


\section{Para publicar na revista Universitas/JUS, acesse $o$ endereço eletrônico www.publicacoesacademicas.uniceub.br.}

Observe as normas de publicação, para facilitar e agilizar o trabalho de edição. 